\title{
Robotic Left Hepatectomy Extended to Caudate Lobe and Common Biliary Duct for Hilar Cholangiocarcinoma
}

\author{
Antoine Camerlo, MD, Héloise Seux, MD, and Regis Fara, MD \\ Department of Digestive Surgery, Hôpital Européen, Marseille, France
}

\begin{abstract}
Background. The safety and efficiency of minimally invasive approaches for liver resection have been confirmed (Wakabayashi in Ann Surg, 2015). However, laparoscopy suffers from several limitations due to technical difficulties, particularly for difficult hepatectomy with lymphadenectomy, biliary, and vascular reconstruction. Robotic assets could improve accessibility for difficult liver resections (Liu in World $\mathrm{J}$ Gastroenterol 25: 1432-1444), (Chou in Zhonghua Wai Ke Za Zhi 58: 230-234, 2020).
\end{abstract}

Patients and methods. A 56-year-old woman was treated for a hilar cholangiocarcinoma, Bismuth $3 \mathrm{~b}$.

Results. A robotic anatomical left hepatectomy extended to caudate lobe and common biliary duct was decided. A Da Vinci X robot was used. The procedure was performed with a second surgeon positioned between the patient's legs. Left hepatectomy was extended to common biliary duct and caudate lobe. A four-hands parenchymal dissection (Camerlo in J Robot Surg, 2020) was performed with laparoscopic ultrasonic dissector and robotic irrigated bipolar, guided by indocyanine green. Axis of deep transection line was maintained using the EndoWrist function and exposure with a fourth arm. No pedicle clamping was necessary. Segment 1 was released with a mediocaudal approach. Lateral portal vein resection was performed after parenchymal transection was completed. Hepaticojejunostomy was done separately to the right anterior and posterior biliary duct. Operation time was $420 \mathrm{~min}$, and estimated

(C) Society of Surgical Oncology 2021

First Received: 29 July 2021

Accepted: 9 November 2021;

Published Online: 7 January 2022

A. Camerlo, MD

e-mail: antoinecamerlo@gmail.com blood loss was $100 \mathrm{ml}$. The postoperative course was uneventful. The patient was discharged on postoperative day 8. Pathological findings revealed a $15-\mathrm{mm}$ hilar cholangiocarcinoma with complete resection and eight lymph nodes, all negative.

Conclusions. Robotic approaches could improve accessibility to minimally invasive liver resection of Klatskin tumor.

Supplementary Information. The online version contains supplementary material available at https://doi.org/10.124 5/s10434-021-11109-4.

DISCLOSURE Drs. A. Camerlo, H. Seux, and R. Fara have no conflicts of interest or financial ties to disclose.

\section{REFERENCES}

1. Wakabayashi G, Cherqui D, Geller DA, Buell JF, Kaneko H, Han HS, et al. Recommendations for laparoscopic liver resection: a report from the second international consensus conference held in Morioka. Ann Surg. 2015;261(4):619-29.

2. Liu R, Wakabayashi G, Kim H-J, Choi G-H, Yiengpruksawan A, Fong $\mathrm{Y}$, et al. International consensus statement on robotic hepatectomy surgery in 2018. World $J$ Gastroenterol. 2019;25(12):1432-44.

3. Chou S, Chang ZY, Zhao GD, Song DD, Zhang X, Hu MG, et al. Robotic hilar cholangiocarcinoma radical resection compared with laparotomy in prognosis. Zhonghua Wai Ke $\mathrm{Za}$ Zhi. 2020;58(3):230-4.

4. Camerlo A, Magallon C, Vanbrugghe C, Chiche L, Gaudon C, Rinaldi Y, et al. Robotic hepatic parenchymal transection: a twosurgeon technique using ultrasonic dissection and irrigated bipolar coagulation. J Robot Surg. 2021;15(4):539-46.

Publisher's Note Springer Nature remains neutral with regard to jurisdictional claims in published maps and institutional affiliations. 